\title{
Computer-aided dental manufacturing technologies used in fabrication of metal frameworks
}

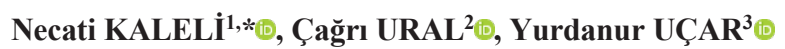 \\ ${ }^{1}$ Department of Dentistry Services, Vocational School of Health Services, Ondokuz Mayıs University, Samsun, Turkey \\ ${ }^{2}$ Department of Prosthodontics, Faculty of Dentistry, Ondokuz Mayıs University, Samsun, Turkey \\ ${ }^{3}$ Department of Prosthodontics, Faculty of Dentistry, Çukurova University, Adana, Turkey
}

\begin{abstract}
\begin{tabular}{lllll}
\hline Received: 22.05 .2020 & $\bullet$ & Accepted/Published Online: 03.12.2020 & Final Version: 19.05 .2021
\end{tabular}
\section{Abstract}

Metal alloys have been used for many years as framework material of dental restorations. The conventional lost-wax and casting method, which was very popular in fabrication of metal frameworks, is now being replaced by computer-aided manufacturing technologies. Computer-aided manufacturing methods offer many advantages, such as standardization and quality in manufacturing, precise fit of restorations, and improved mechanical strength. Digital technologies used in fabrication of metal frameworks are simply classified as subtractive and additive computer-aided manufacturing systems, and each has their own subdivisions, which show differences in the used technology. This review summarizes computeraided systems used in fabrication of metal frameworks in terms of use in dental practice, advantages, and disadvantages and provides clinical recommendations.
\end{abstract}

Keywords: computer-aided manufacturing, digital dentistry, metal frameworks, metal manufacturing

\section{Introduction}

The use of metal alloys as a framework under superstructure material has always been a choice for dentists due to their excellent mechanical properties (Kaleli and Saraç, 2017b). Manufacturing of metal frameworks in the professional sense first started with the introduction of the lost-wax casting method, which was adapted from the jewelry industry (Van Noort, 2012), and this old technology is still used for fabricating metal frameworks (Kaleli and Saraç, 2017a). However, casting of base metal alloys has some drawbacks. Casting process involves several time-consuming steps, of which each need technical sensitivity (Sun and Zhang, 2012). Moreover, cast frameworks may show some impurities within the structure, which negatively affect the mechanical properties (Willer et al., 1998; Pasali et al., 2018).

Dentistry is continuously evolving, and more and more dentist join to this field day by day, and dental laboratories have to use high performance manufacturing technologies to meet the commercial needs. With the introduction of computer-aided design and computer-aided manufacturing systems (CAD-CAM), a new era has begun in metal manufacturing. CAD-CAM systems simply work as follows: (1) the computer-aided impression (CAI) data, which is obtained by intra-oral scanners (IOSs) or laboratory model scanners, (2) is processed by the CAD software, (3) and then the final design is turned into a physical part by the CAM unit (Alghazzawi, 2016). This digital workflow has overcome the problems resulted from casting imperfections and have offered easier, faster, and more predictable manufacturing solutions as well as improved mechanical properties of metal frameworks (Sun and Zhang, 2012; Van Noort, 2012; Alghazzawi, 2016; Braian et al., 2018). The computer-aided manufacturing systems used in dentistry are classified as subtractive manufacturing technologies and additive manufacturing technologies, and each system has advantages and disadvantages when compared with each other (Van Noort, 2012; Alghazzawi, 2016). This review illuminates the current computer-aided manufacturing systems used in fabrication of metal frameworks (Fig. 1) in terms of manufacturing time, laboratory cost, ease of application, preferability, and clinical recommendations.

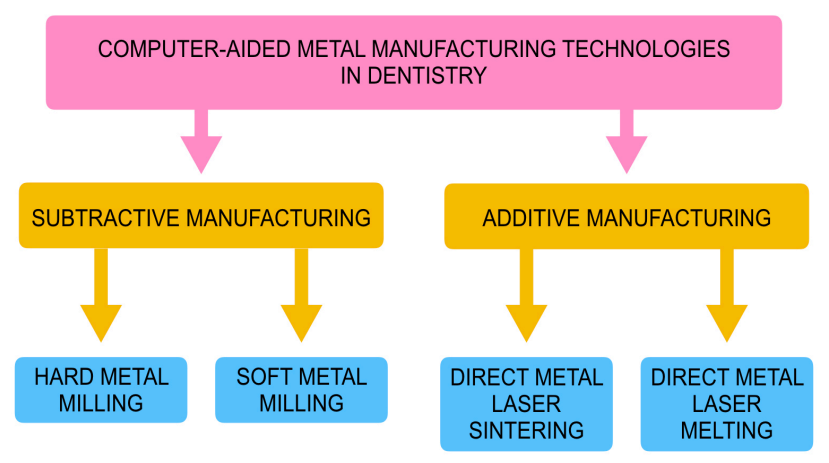

Fig. 1. Computer-aided metal manufacturing technologies in dentistry 


\section{Subtractive metal manufacturing}

Subtractive manufacturing is simply based on the milling technology, of which uses sharp cutting tools to cut solid metal blocks under the control of computer software. This technology reduces overall manufacturing time, and dental restorations with complex geometries, which are difficult to be made by using conventional workflow, could be easily fabricated (Van Noort, 2012). However, the accuracy of the milling process is limited by the diameter of the milling equipment (Örtorp et al., 2011; Bosch et al., 2014). Any surface detail smaller than the smallest milling bur, which is in the bur tool set, will be over milled and hence result in missed geometrical details in the final restoration (Alghazzawi, 2016).

The milling process of metal alloys can be either dry or wet milling, which depends on the alloy system (Alghazzawi, 2016). In the past, only fully sintered hard alloys (FHA) were used, which needed wet milling (Alghazzawi, 2016). The FHA blanks are fabricated under standardized conditions so that they lack structural defects, porosities, and residual stresses (Braian et al., 2018). Therefore, metal frameworks, which are fabricated by using FHA blanks, have high-level of structural homogeneity and improved mechanical properties (Willer et al., 1998; Braian et al., 2018). Titanium (Ti) metal blanks are mainly used for fabricating custom implant abutments and bars, whereas the cobalt-chromium (Co-Cr) metal blanks are mainly used for fabricating single or multiple-unit metal frameworks of fixed dental restorations (Alghazzawi, 2016). In particular, the hard metal milling provides improved fit in fabrication of full-arch implant-supported metal frameworks, which involves both teeth and gingival parts (Srivastava and Bidra, 2020). However, the milling of base metal alloys takes too much time and their hardness leads to rapid abrasion of milling tools, which increases the laboratory cost (Sun and Zhang, 2012; Krug et al., 2015; Park et al., 2016). As a solution, manufacturers have come up with new commercial manufacturing strategies (Park et al., 2016). Today, presintered soft alloys (PSA) are available for fabrication of metal frameworks (Park et al., 2016; Kim et al., 2017; Pasali et al., 2018), and these wax-like metal blanks need dry milling (Stawarczyk et al., 2014; Alghazzawi, 2016; Park et al., 2016). The PSA blanks are manufactured by compressing $\mathrm{Co}-\mathrm{Cr}$ metal powders under isostatic pressure (Lambert et al., 2017), and they can be easily milled with minimum abrasion of milling equipment (Krug et al., 2015; Park et al., 2016; Kim et al., 2017). Moreover, the manufacturing process is completed sooner when compared to hard metal milling (Krug et al., 2015; Park et al., 2016; Kim et al., 2017). Following the milling process, the PSA frameworks are sintered to full density under argon protective gas atmosphere, and this sintering process results in an approximately $10 \%$ to $11 \%$ contraction within the structure, which is similar to sintering process of pre-sintered zirconia restorations (Stawarczyk et al., 2014; Park et al., 2016; Kim et al., 2017; Pasali et al., 2018). Soft metal alloys may be considered as cost-efficient for metal-ceramic restorations; however, only Co-Cr soft metal alloys are available in the market. Therefore, they are not indicated for fabricating custom implant abutments and bar structures because of that titanium is the first option for custom solutions in implantsupported metal frameworks (Lambert et al., 2017).

Yet, subtractive manufacturing is a wasteful process because the amount of removed material is more than that used in the final metal product. Moreover, the subtractive milling technologies are not efficient in contouring of undercuts and complex internal geometries due to limited access of the milling tools associated with the size of milling burs and the working axis of the milling machines (Van Noort, 2012; Revilla-León and Özcan, 2017). Material waste and missing details associated with milling process can be minimized by using additive manufacturing methods (Van Noort, 2012).

\section{Additive metal manufacturing technologies}

The American Society for Testing Materials (ASTM) defines the additive manufacturing as the process of joining materials to make parts from 3D model data, usually layer upon layer (Van Noort, 2012). Unlike subtractive manufacturing, additive manufacturing strategies eliminate the waste of raw material and provides fabrication of actual parts, which have complex structural geometries (Sun and Zhang, 2012; Van Noort, 2012; Alghazzawi, 2016; Revilla-León and Özcan, 2017). Several additive manufacturing systems are used in dental applications; of these, laser sintering technologies stand out for metal manufacturing (Sun and Zhang, 2012; Van Noort, 2012; Revilla-León and Özcan, 2017). In the laser sintering system, the CAD data is segmented to multiple layers at micron level, and each layer is fabricated by using a high-power laser source that transmits the laser beams to the powdered metal particles on the surface layer and hence fuses them together. This process continues layer by layer until the fabrication of metal frameworks is completed (Santos et al., 2006; Sun and Zhang, 2012).

Laser sintering machines, which are used for dental applications, can be classified according to their melting method as follows: (1) direct metal laser sintering (DMLS), (2) direct metal laser melting (DMLM). DMLS is based on partial melting of metal particles, whereas DMLM is based on complete melting of metal particles (Ekren et al., 2018; Ucar and Ekren, 2018; Kaleli et al., 2019a; Kaleli et al., 2019b; Kaleli and Ural, 2020). The final product reaches higher density when the process is based on complete melting (Santos et al., 2006; Ekren et al., 2018; Kaleli and Ural, 2020). Regardless of the melting strategies, all metal frameworks are subjected to additional heat treatment in normalization furnaces, which is defined as annealing, after the fabrication process is completed (Revilla-León and Özcan, 2017; Tulga, 2018). This post-processing procedure provides improved ductility, relief from internal stresses, structural homogeneity. Although the duration and temperature range of the annealing process varies depending on the sintering parameters, alloy powder, and laser sintering machines (Tulga, 2018), a common 
point for all annealing programs is that the process should be conducted under protective gas atmosphere to decrease the interparticle distance and bilayer thickness (Ayyldız et al., 2013; Tulga, 2018).

The laser sintering is conducted under control of several processing parameters, which affect the mechanical properties of final product. One of the important parameters is the layer thickness of sintering process (Kaleli et al., 2019a; Kaleli et al., 2019b; Kaleli and Ural, 2020). The laser sintering systems used in metal manufacturing generally work with the principle of powder-bed fusion. In powder-bed fusion system, the powdered metal particles are swept onto the build platform by the rake, which is a metal, ceramic, or polymer-coated bar. After the laser beam wave passed, the building platform is lowered, and a new layer is swept onto the build platform. This processing parameter simply determines how much metal powder will be swept onto the build platform between each laser wave (Sames et al., 2016). The layer thickness directly affects the manufacturing time. The duration of the laser sintering process considerably decreases when the layer thickness is increased (Sames et al., 2016); however, this brings up a new challenge. When the layer thickness exceeds a certain threshold, which is higher than the penetration depth of laser source, the "balling effect" may occur. This phenomenon is defined as "porosity" or "delamination" that causes a poor interlayer bond between the fresh powder and previously sintered layer (Gu and Shen, 2009). As for dental applications, the laser sintering process is conducted approximately with a layer thickness of $20 \mu \mathrm{m}$ (Koutsoukis et al., 2015), and this cannot be further decreased because of that setting the layer thickness lower than $20 \mu \mathrm{m}$ increases the porosity within the structure (Mazzoli, 2013). Another important processing parameter is the laser scanning speed, which is mostly under the operator's control (Kaleli and Ural, 2020). Increasing the laser scanning speed decreases the manufacturing time (Senthilkumaran et al., 2009); however, the linear energy density of the laser input decreases as well, and this results in a balling effect and transverse shrinkage distortion in the interparticle zone (Wang et al., 2007; Zhang et al., 2012). On the other hand, if the laser scanning speed decreases too much, the high energy of the laser input may cause rapid evaporation of the raw metal particles (Lu et al., 2017). Dental laboratories have their own manufacturing considerations, which are mostly based on cost and manufacturing time. Nevertheless, the best manufacturing strategy is to follow the manufacturer's guidelines.

The laser sintering is a cost-efficient and rapid manufacturing method for dental laboratories. Yet, one of the important disadvantages of this system is the support removal followed by finishing procedures. The laser sintered metal frameworks are fabricated on lattice support structures (Fig. 2), which prevents metal frameworks from deformation caused by gravity or growth stress (Sames et al., 2016).

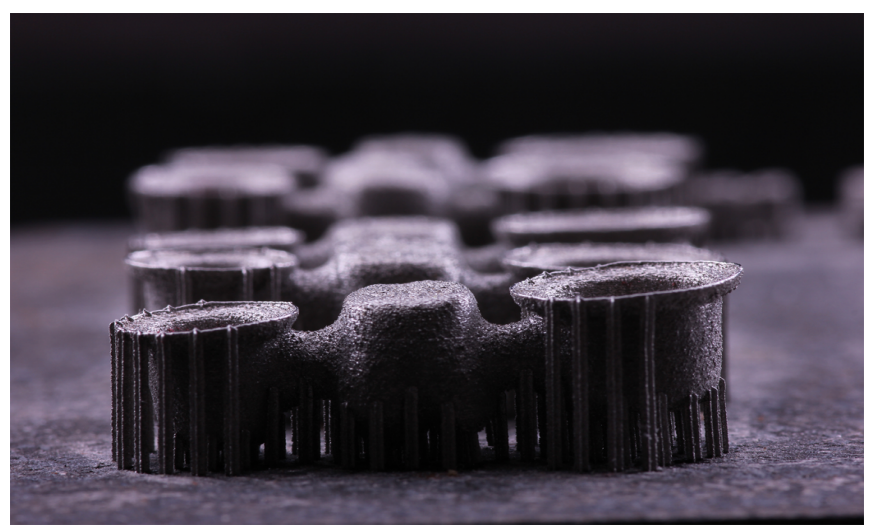

Fig. 2. Laser-sintered metal framework on lattice supports

After the fabrication and subsequent annealing processes, the supports are removed by using tungsten carbide burs. However, the computer-aided manufacturing continues with conventional manual manufacturing. Moreover, the raw metal powder undergoes rapid melting and then annealing, and these thermal processes may affect the adaptation of metal frameworks. Furthermore, the laser sintering systems are unable to create smooth or planar frameworks like milling technologies (Fig. 3). Therefore, laser sintering systems are not preferred particularly in fabrication of full-arch implantsupported frameworks or custom implant-supported solutions (Ciocca et al., 2019).

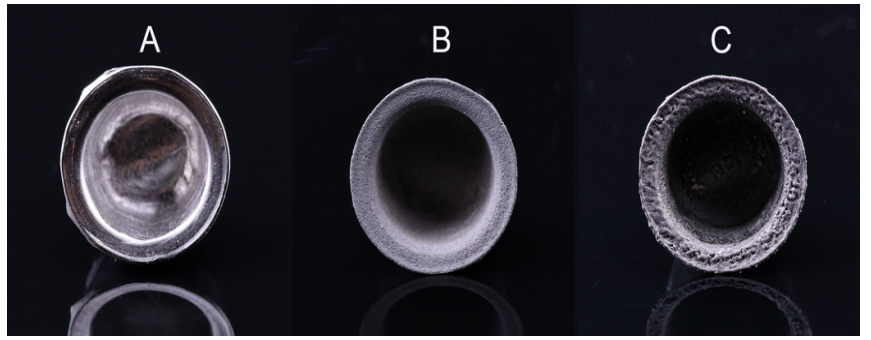

Fig. 3. Metal frameworks fabricated with different Computer-aided manufacturing technologies: hard metal milling (a), soft metal milling (b) and direct metal laser melting (c)

Recently, a new manufacturing solution, which is called hybrid manufacturing, has been proposed to fabricate implantsupported metal frameworks. In the hybrid manufacturing system, the main part of the metal framework is fabricated by using laser sintering machine, and the following finishing process is completed by $3 \mathrm{D}$ processing manufacturing machines using milling to refine the over-contoured areas. This new manufacturing strategy promises to combine the advantages of both laser sintering and milling technologies (Ciocca et al., 2019).

\section{Conclusion}

The clinicians should consider advantages and disadvantages of both subtractive and additive manufacturing methods, and they should select the manufacturing method according to the cases. Laser sintering technologies offer economical solutions when compared to milling technologies. Nevertheless, milling systems are more preferable in custom implant solutions. Using only one manufacturing system may not be efficient for all cases. 


\section{References}

1. Alghazzawi, T.F., 2016. Advancements in CAD/CAM technology: Options for practical implementation. J. Prosthodont. Res. 60, 7284.

2. Ayyıldız, S., Soylu, E.H., İde, S., Kılıç, S., Sipahi, C., Pişkin, B., Gökçe, H.S., 2013. Annealing of Co-Cr dental alloy: effects on nanostructure and Rockwell hardness. J. Adv. Prosthodont. 5, 471478.

3. Bosch, G., Ender, A., Mehl, A., 2014. A 3-dimensional accuracy analysis of chairside CAD/CAM milling processes. J. Prosthet. Dent. 112, 1425-1431.

4. Braian, M., Jönsson, D., Kevci, M., Wennerberg, A., 2018. Geometrical accuracy of metallic objects produced with additive or subtractive manufacturing: A comparative in vitro study. Dent. Mater. 34, 978-993.

5. Ciocca, L., Meneghello, R., Savio, G., Scheda, L., Monaco, C., Gatto, M.R., Micarelli, C., Baldissara, P., 2019. Manufacturing of metal frameworks for full-arch dental restoration on implants: A comparison between milling and a novel hybrid technology. J. Prosthodont. 28, 556-563.

6. Ekren, O., Ozkomur, A., Ucar, Y., 2018. Effect of layered manufacturing techniques, alloy powders, and layer thickness on metal-ceramic bond strength. J. Prosthet. Dent. 119, 481-487.

7. Gu, D., Shen, Y., 2009. Balling phenomena in direct laser sintering of stainless-steel powder: Metallurgical mechanisms and control methods. Mater. Des. 30, 2903-2910.

8. Kaleli, N., Saraç, D., 2017a. Comparison of porcelain bond strength of different metal frameworks prepared by using conventional and recently introduced fabrication methods. J. Prosthet. Dent. 118, 76-82.

9. Kaleli, N., Saraç, D., 2017b. Influence of porcelain firing and cementation on the marginal adaptation of metal-ceramic restorations prepared by different methods. J. Prosthet. Dent. 117, 656-661.

10. Kaleli, N., Ural, Ç., 2020. Digital evaluation of laser scanning speed effects on the intaglio surface adaptation of laser-sintered metal frameworks. J. Prosthet. Dent. 6, 874.e1-874.e7.

11. Kaleli, N., Ural, Ç., Küçükekenci, A.S., 2019a. The effect of layer thickness on the porcelain bond strength of laser-sintered metal frameworks. J. Prosthet. Dent. 122, 76-81.

12. Kaleli, N., Ural, Ç., Özköylü, G., Duran, İ., 2019b. Effect of layer thickness on the marginal and internal adaptation of laser-sintered metal frameworks. J. Prosthet. Dent. 121, 922-928.

13. Kim, E.H., Lee, D.H., Kwon, S.M., Kwon, T.Y., 2017. A microcomputed tomography evaluation of the marginal fit of cobalt-chromium alloy copings fabricated by new manufacturing techniques and alloy systems. J. Prosthet. Dent. 117, 393-399.

14. Koutsoukis, T., Zinelis, S., Eliades, G., Al-Wazzan, K., Rifaiy, M.A., Al Jabbari, Y.S., 2015. Selective laser melting technique of Co-Cr dental alloys: A review of structure and properties and comparative analysis with other available techniques. J. Prosthodont. 24, 303-312.

15. Krug, K.P., Knauber, A.W., Nothdurft, F.P., 2015. Fracture behavior of metal-ceramic fixed dental prostheses with frameworks from cast or a newly developed sintered cobalt-chromium alloy. Clin. Oral. Investig. 19, 401-411.

16. Lambert, H., Durand, J.C., Jacquot, B., Fages, M., 2017. Dental biomaterials for chairside CAD/CAM: State of the art. J. Adv. Prosthodont. 9, 486-495.
17. Lu, Y., Gan, Y., Lin, J., Guo, S., Wu, S., Lin, J., 2017. Effect of laser speeds on the mechanical property and corrosion resistance of CoCrW alloy fabricated by SLM. Rapid. Prototyp. J. 23, 28-33.

18. Mazzoli, A., 2013. Selective laser sintering in biomedical engineering. Med. Biol. Eng. Comput. 51, 245-256.

19. Örtorp, A., Jönsson, D., Mouhsen, A., Von Steyern, P.V., 2011. The fit of cobalt-chromium three-unit fixed dental prostheses fabricated with four different techniques: A comparative in vitro study. Dent. Mater. 27, 356-363.

20. Park, J.K., Kim, H.Y., Kim, W.C., Kim, J.H., 2016. Evaluation of the fit of metal ceramic restorations fabricated with a pre-sintered soft alloy. J. Prosthet. Dent. 116, 909-915.

21. Pasali, B., Sarac, D., Kaleli, N., Sarac, Y.S., 2018. Evaluation of marginal fit of single implant-supported metal-ceramic crowns prepared by using presintered metal blocks. J. Prosthet. Dent. 119, 257-262.

22. Revilla-León, M., Özcan, M., 2017. Additive manufacturing technologies used for 3D metal printing in dentistry. Curr Oral Health Rep. 4, 201-208.

23. Sames, W.J., List, F., Pannala, S., Dehoff, R.R., Babu, S.S., 2016. The metallurgy and processing science of metal additive manufacturing. Int. Mater. Rev. 61, 315-360.

24. Santos, E.C., Shiomi, M., Osakada, K., Laoui, T., 2006. Rapid manufacturing of metal components by laser forming. Int. J. Mach. Tools. Manuf. 46, 1459-1468.

25. Senthilkumaran, K., Pandey, P.M., Rao, P., 2009. Influence of building strategies on the accuracy of parts in selective laser sintering. Mater. Des. 30, 2946-2954.

26. Srivastava, A., Bidra, A.S., 2020. Milled cobalt-chromium metal framework with veneered porcelain for a complete-arch fixed implant-supported prosthesis: A clinical report. J. Prosthet. Dent. $123,367-372$.

27. Stawarczyk, B., Eichberger, M., Hoffmann, R., Noack, F., Schweiger, J., Edelhoff, D., Beuer, F., 2014. A novel CAD/CAM base metal compared to conventional CoCrMo alloys: An in-vitro study of the long-term metal-ceramic bond strength. Oral. Health. Dent. Manag. 13, 446-452.

28. Sun, J., Zhang, F.Q., 2012. The application of rapid prototyping in prosthodontics. J. Prosthodont. 21, 641-644.

29. Tulga, A., 2018. Effect of annealing procedure on the bonding of ceramic to cobalt-chromium alloys fabricated by rapid prototyping. J. Prosthet. Dent. 119, 643-649.

30. Ucar, Y., Ekren, O., 2018. Effect of layered manufacturing techniques, alloy powders, and layer thickness on mechanical properties of Co-Cr dental alloys. J. Prosthet. Dent. 120, 762-770.

31. Van Noort, R., 2012. The future of dental devices is digital. Dent. Mater. 28, 3-12.

32. Wang, R.J., Wang, L., Zhao, L., Liu, Z., 2007. Influence of process parameters on part shrinkage in SLS. Int. J. Adv. Manuf. Technohol. 33, 498-504.

33. Willer, J., Rossbach, A., Weber, H.P., 1998. Computer-assisted milling of dental restorations using a new CAD/CAM data acquisition system. J. Prosthet. Dent. 80, 346-353.

34. Zhang, B., Liao, H., Coddet, C., 2012. Effects of processing parameters on properties of selective laser melting $\mathrm{Mg}-9 \% \mathrm{Al}$ powder mixture. Mater. Des 34, 753-758. 